\title{
Effect of Variant End of Injection Period on Combustion Process of Biodiesel Combustion
}

\author{
Amir Khalid ${ }^{1, *}$, Noorpuspadilla Baharuddin ${ }^{1}$, Azwan Sapit ${ }^{1}$, Azahari Razali ${ }^{1}$, and \\ Norrizam Jaat ${ }^{2}$ \\ ${ }^{1}$ Combustion Research Group (CRG), Centre for Energy and Industrial Environment Studies (CEIES), \\ Faculty of Mechanical and Manufacturing Engineering, Universiti Tun Hussein Onn Malaysia, 86400 \\ Batu Pahat, Johor, Malaysia \\ ${ }^{2}$ Automotive Research Group (ARG), Centre for Energy and Industrial Environment Studies (CEIES), \\ Faculty of Mechanical and Manufacturing Engineering, Universiti Tun Hussein Onn Malaysia, 86400 \\ Batu Pahat, Johor, Malaysia
}

\begin{abstract}
Biodiesel is an alternative fuel as a replacement to the standard diesel fuel in combustion diesel engine. The biodiesel fuel has a significantly influences throughout the combustion process and exhaust emission. The purpose of this research is to investigate the combustion process behavior during the End of Injection (EOI) period and operates under variant conditions using Rapid Compression Machine (RCM). Experimental of RCM is used to simulate a combustion process and combustion characteristics of diesel engine combustion. Three types of biodiesel blend which are B5, B10 and B15 were tested at several injection pressures of $80 \mathrm{MPa}, 90 \mathrm{MPa}$ and $130 \mathrm{MPa}$ under different ambient temperatures, $750 \mathrm{~K}$ to $1100 \mathrm{~K}$. The results of this study showed that the ignition delay slightly reduced with increasing the content of biodiesel blends from B5, B10 and B15 and became more shorten as the injection pressure been enhanced. As the injection pressure increased, the behavior of combustion pressure at end of injection is reduced, radically increased the NOX emission. It is noted that the process of combustion at the end of injection increased as the ambient temperature is rising. In fact, higher initial ambient temperature improved the fuel atomization and mixing process. Under the biodiesel combustion with higher ambient temperature condition, the exhaust emission of $\mathrm{CO}, \mathrm{O} 2$, and $\mathrm{HC}$ became less but increased in NOX emission. Besides, increased in blends of biodiesel ratio are found to enhance the combustion process, resulted a decreased in $\mathrm{HC}$ emissions.
\end{abstract}

\section{Introduction}

Nowadays, the major issues of automotive industry facing are to control fuel consumption, increasing the price of standard diesel fuel and pollutant emissions. Due to this major problem, biodiesel is one of the potential alternative fuels for diesel fuel, which could keep

* Corresponding author: amirk@uthm.edu.my 
the high efficiency in diesel engines. Basically, biodiesel [1-3] is found as the alternative fuels to reduce emission of hydrocarbon ( $\mathrm{HC})$, carbon monoxide (CO), and particulate matter (PM) but it affects to the increasing of oxides of nitrogen (NOX) emission. The main usage of biodiesel is lead to the highest reduction in $\mathrm{HC}, \mathrm{CO}$ and $\mathrm{PM}$ emissions without any power losses, but it also increased in fuel consumption and NOX emission on diesel engine with no modification or special fuelling equipment [4]. Although the regulation of NOX emission is very strict now, but biodiesel still can eligible to satisfy the stringent future emissions policies and the lack of fossil fuels [5-7]. In diesel engine, ignition delay is a major factor to determine the rapid pressure rise at the initial burning stage and subsequent combustion stage. The ignition delay, which is meant the duration or time period between the start of injection and ignition of the combustion. The process in ignition delay divided into physical and chemical processes. Physical delay processes correspond to the mixture formation that involving atomization, penetration, entrainment and vaporization. Meanwhile, the chemical delay to the time necessary to get an exponential increase in the chemical reaction rate which consist processes such as fuel decomposition and oxidation [8]. Increase in ignition delay has been often longer than the fuel injection duration, which causes ignition dwell, defined as the duration between the EOI and the start of combustion. With positive ignition dwell, mixing process occurring near or after the EOI dominate the following combustion and emission formation [9-10].

H. M. Pated [11] studied the fuel injection system in diesel engine and found that the fuel injection system can be improved the engine operation characteristics. The injection pressure increased influence the spray atomization and mixture preparation process of biodiesel fuel [12]. While the injection duration dependence on the fuel properties such as bulk modulus, viscosity and density [13]. The influence of high injection pressure can help attain better combustion of fuel which will result in low $\mathrm{HC}$ emission, but increased in the values of NOX emission [14]. The behavior of biodiesel fuel at the end of injection is poorly understood, yet it has important implications regarding to the diesel engine emissions. Recent researches have shown that at the end of injection, an entrainment wave is created which caused the fuel spray to entrain rapidly with the ambient gas. This rapid entrainment creates a dilute mixture of fuel that may be a source of unburned hydrocarbon emissions [15-16]. Unburned hydrocarbons (UHC) are fuel and lubrication particles that did not burn completely and smaller non-equilibrium particles of partially burned fuel. Besides, the emission also consists of carbon monoxide (CO) due to the incomplete air-fuel mixing which caused by the very short engine cycle time. In this research, the characteristics of the combustion process are investigated with focused on the behavior at the end of injection in terms of pressure with changing ambient condition and injection parameters. The experimental study was performed in a Rapid Compression Machine [16]. The detail behavior of combustion at the end of injection was collected by PICO Scope 3000 series.

\section{Methodology}

The biodiesel from Crude Palm Oil (CPO) is then blended with diesel in various concentrations for prepared the biodiesel blends of 5vol\% (B5), 15vol\% (B10) and $15 \mathrm{vol} \%$ (B15). During blending process, the mixture was stirred at $70 \mathrm{oC}$ for 1 hour with the rotating blade speed maintained at 270 RPM. The properties of biodiesel are listed as illustrates in Table 1. The experimental apparatus can be divided into several systems such as rapid compression machine, single-shot common rail system, data acquisition system 
and exhaust emission measurement system. Moreover, the exhaust emission was measured by gas analyzer.

Table 1. Properties of Biodiesel

\begin{tabular}{|l|c|c|c|}
\hline \multirow{2}{*}{ Fuel Type } & \multicolumn{3}{|c|}{ Properties } \\
\cline { 2 - 4 } & $\begin{array}{c}\text { Density } \\
\left(\mathbf{g} / \mathbf{m}^{\mathbf{3}}\right)\end{array}$ & $\begin{array}{c}\text { Kinematic } \\
\text { Viscosity } \\
\text { (Cp) }\end{array}$ & $\begin{array}{c}\text { Water } \\
\text { Content } \\
\text { (ppm) }\end{array}$ \\
\hline B5 & 0.837 & 3.0 & 120.1 \\
\hline B10 & 0.838 & 2.9 & 158.6 \\
\hline B15 & 0.840 & 3.0 & 219 \\
\hline
\end{tabular}

A schematic diagram of Rapid Compression machine is shown in Figure 1, together with an outline of the fuel injection system. A free piston is placed at the left side of the cylinder paneled by an orifice plate and partitioned by a diaphragm as a start of the experiment. Then, the driver chamber and the pressure reservoir are filled with nitrogen gas to allow the diaphragm could withstand the pressures in order to avoid the damage of diaphragm. Once the valve is opened, the pressure inside the driver increased immediately and caused the diaphragm burst and the piston is travelled onto a tapered stop ring installed in front of the combustion chamber. Fuel was injected after a fixed interval from the time the piston stopped. The measured air temperature and pressure at the start of injection were used to identify the combustion behavior at EOI by the Pico Scope 3000 series. Table 2 summarizes the experimental conditions in this research.

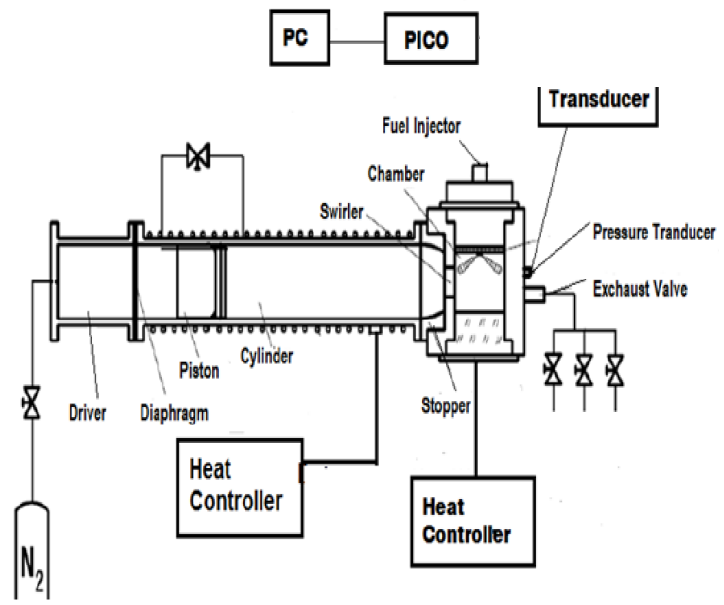

Fig. 1. Schematic Diagram of RCM

Table 2. Specifications of experimental

\begin{tabular}{|c|c|c|}
\hline \multirow{4}{*}{ Fuel } & Injector type & $\begin{array}{c}6 \text { holes, } \emptyset= \\
0.16 \mathrm{~mm}\end{array}$ \\
\cline { 2 - 3 } & Fuel type & $\begin{array}{c}\mathrm{B} 5, \mathrm{~B} 10, \\
\mathrm{~B} 15\end{array}$ \\
\cline { 2 - 3 } & $\mathrm{P}_{\mathrm{inj}}[\mathrm{MPa}]$ & $\begin{array}{c}80,90 \text { and } \\
130\end{array}$ \\
\cline { 2 - 3 } & $\mathrm{q}_{\mathrm{i}}[\mathrm{ml}]$ & 0.04 \\
\hline $\begin{array}{c}\text { Ambient } \\
\text { Condition } \\
\text { (inside } \\
\text { chamber) }\end{array}$ & $\mathrm{T}_{\mathrm{i}}\left[{ }^{\circ} \mathrm{C}\right]$ & 70,80 \\
\cline { 2 - 3 } & $\mathrm{r}_{\mathrm{s}}[\mathrm{m} / \mathrm{s}]$ & 19 \\
\cline { 2 - 3 } & $\mathrm{\rho}^{2}\left[\mathrm{~kg} / \mathrm{m}^{3}\right]$ & 16.6 \\
\hline & $\mathrm{O}_{2}[\mathrm{vol} \%]$ & 21 \\
\hline
\end{tabular}




\section{Result and discussion}

The aim of this study was to investigate the influence of the combustion behavior during the End of Injection (EOI) under different parameters with biodiesel blends in the Rapid Compression Machine (RCM). Regarding with this purpose, a comparison between three types of blended biodiesel was investigated in this experiment. For the clarity purposed, the data experiments included emissions under variant conditions in EOI were discussed first. Effects of pressure at EOI on injection duration under variant injection pressure with biodiesel blended with Diesel used were investigated. The initial charging pressure investigated was $\mathrm{Pc}=0.1 \mathrm{MPa}$, which corresponded to the ambient densities of $\rho=16.6$ $\mathrm{kg} / \mathrm{m} 3$. The others parameter were kept constant with swirl velocity $\mathrm{rs}=19 \mathrm{~m} / \mathrm{s}$. Fuel was injected by a 6-hole injector with hole-diameter of $0.16 \mathrm{~mm}$ and variant injection pressures of Pinj=80 MPa, $90 \mathrm{MPa}$ and $130 \mathrm{MPa}$.

Figure 2 to Figure 4 shows the characteristics of variant injection pressures at EOI with three different percentages of biodiesel blends. The measurement pressure at EOI of B5 against the duration injection, in which the time elapsed from begin of injection as shown in Figure 2. Fuel injection began at a predetermined time after the piston is stopped in front of the combustion chamber. A decreased in pressure can be identified due to the fuel vaporization, fuel vapor heated and heat transferred until combustion occurred, while the pressure reached the peak after the EOI.

It showed that the pressure inside the combustion chamber at EOI with the low injection pressure, $80 \mathrm{MPa}$ and $90 \mathrm{MPa}$ was higher compared to the high injection pressure at $130 \mathrm{MPa}$ for B5 biodiesel blends.

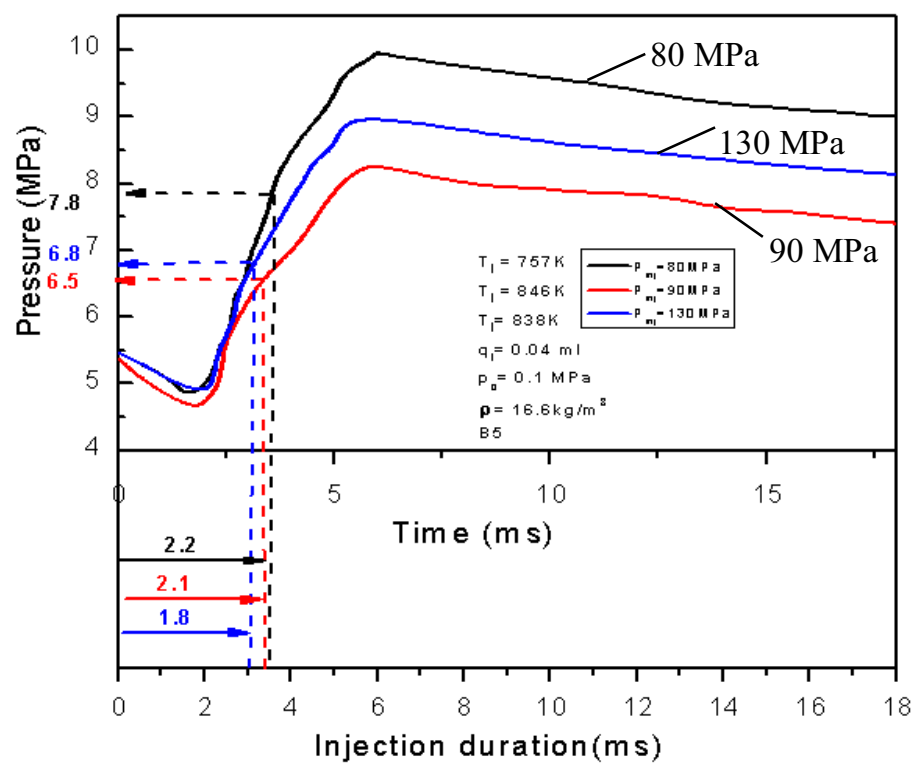

Fig. 2. Variation of Injection duration of B5 blend diesel at different Injection Pressure 


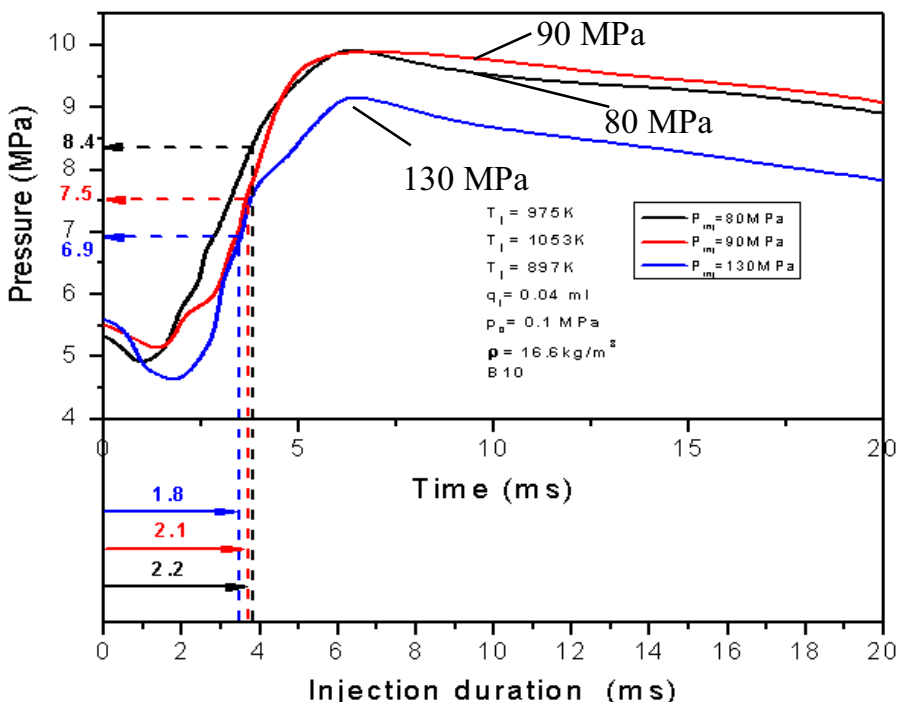

Fig. 3. Variation of Injection duration of B10 blend diesel at different Injection Pressure

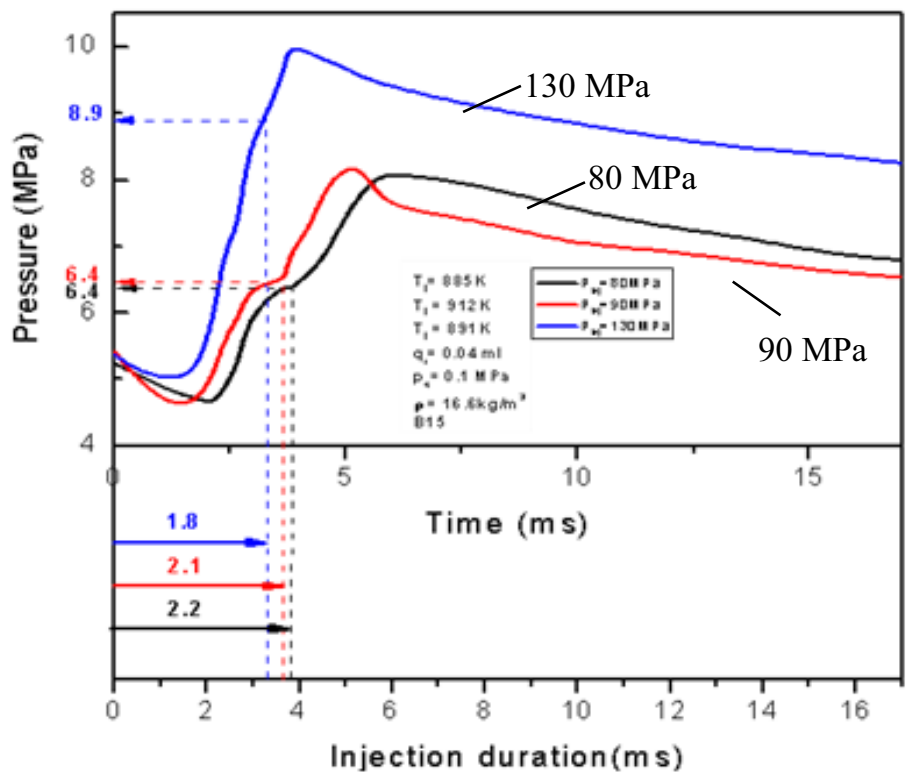

Fig. 4. Variation of Injection duration of B15 blend diesel at different Injection Pressure

B10 biodiesel did not show major changes along with the increased of injection pressure at EOI as illustrated in Figure 3. It can be seemed that, as the injection pressure decreased, the pressure at the EOI became promoted. On the contrary, Figure 4 clearly shows that higher injection pressure at EOI with $130 \mathrm{MPa}$ under B5 of biodiesel blend, which is assumed as the reason of value of viscosity. On top of that, the result showed the injection duration for B5, B10 and B15 are slightly reduced with increased the fuel injection pressure. Possible reason predicted is the higher biodiesel blends (B15) has higher 
density due to the higher density of biodiesel. High injection pressure promoted mixture formation during the ignition delay period and large amount of combustible mixture is formed. Therefore, dark flame developed widely at spray tip region and between sprays before the appearance of bright flame after the ignition. Furthermore, bright flame has less intensity due to well mixing. Figure 5 illustrates the exhaust emissions of the experiment measured by an exhaust gas analyzer for different injection pressures and biodiesel blends. It can be seen that the higher the injection pressure, the more NOx is observed and less HC exhaust emission. Consistent with previous research, the NOx emission for biodiesel blends fuel is gradually increasing with the fuel injection pressure.

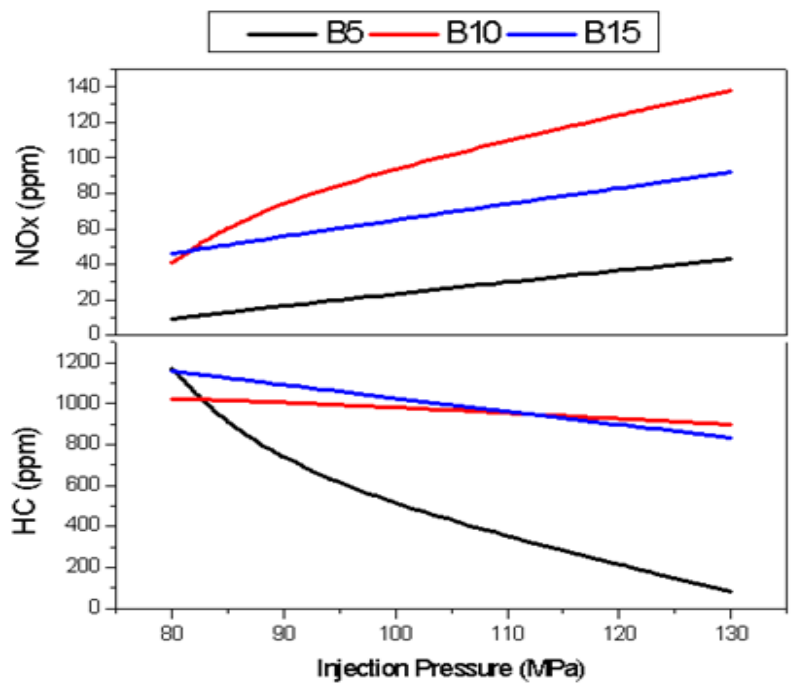

Fig. 5. Effect of pressure at EOI with variant injection temperature towards NOx and HC exhaust emission

\section{Conclusion}

In this paper, a rapid compression machine has been developed to study the basic aspects of the diesel combustion phenomenon. A satisfactory performance has been obtained, a study of combustion behavior at EOI toward the emission. From a series of tests carried out on this compression machine, the following conclusions are obtained:

- The injection duration for B5, B10 and B15 depends with the fuel injection pressure. Dependence of the injection duration, due to the relatively lower fuel properties. Increasing injection pressure and injection duration influences to the NOX emission. Nevertheless, a change of injection pressure is seemed to have higher impact on NOX emission than change in injection duration.

- From the visualization of combustion and emission by gas analyzer with the highest variant ambient temperature towards to the chamber pressure at $\mathrm{EOI}, \mathrm{CO}, \mathrm{O} 2$, and $\mathrm{HC}$ reduction are proven but the increase in NOX emission.

The authors also would like to thank the Ministry of Higher Education Malaysia for supporting this research under Exploratory Research Grant Scheme (ERGS) vot. E032. 


\section{References}

1. A. Khalid, N. Jaat, A. Sapit, A. Razali, B. Manshoor, I. Zaman, A.A. Abdullah, International Journal of Automotive and Mechanical Engineering, 11, 2447 (2015)

2. B. Tesfa, R. Mishra, F. Gu, A.D. Ball, Combustion Characteristics of CI Engine Running with Biodiesel blends, International Conference on Renewable Energies and Power Quality, Las Palmas de Gran Canaria (2011)

3. A. Khalid, N. Tamaldin, M. Jaat, M. F. M. Ali, B. Manshoor, I. Zaman, Procedia Eng., 68, 225 (2013)

4. S. Chandrasekar, R. Niranchan, V. S., J.S. Leon, Effect of Cooled EGR in Combustion Characteristics of a Direct Injection CI Engine Fuelled with Biodiesel Blend, International Journal of Mechanical, Aerospace, Industrial, Mechatronic and Manufacturing Engineering, 73, 109 (2013)

5. A. Demirbas, Energ. Convers. Manage., 50, 2239 (2009).

6. M. Jaat, A. Khalid, B. Manshoor, S.M. Basharie, H. Ramsy, Appl. Mech. Mater., 465, 265 (2014)

7. M.P.B. Musculus, T. Lachaux, L.M. Pickett, C. Idicheria, Hydrocarbon Emissions in Low-Temperature-Combustion Diesel Engines, 724, 776 (SAE International, 2007)

8. S. Kook, L.M. Pickett, M.P.B. Musculus, SAE Int. J. Engines, 2, 1194 (2009)

9. A. Khalid, M.D. Anuar, Y. Ishak, B. Manshoor, A. Sapit, M. Leman, I. Zaman, Emissions characteristics of small diesel engine fuelled by waste cooking oil, $4^{\text {th }}$ International Conference on Production, Energy and Reliability, 13, 6 (2014)

10. O.A. Kuti, J. Zhua, K. Nishidaa, X. Wang, Z. Huang, Fuel, 104, 838 (2013)

11. H.M. Patel, Design and Optimization of Fuel Injection System in Diesel Engine Using Biodiesel - A Review, International Journal of Innovations in Engineering and Technology, 2, 70 (2013)

12. S. Lee, S. Park, Y. Daisho, P. I. Mech. Eng. D-J. Aut., 218, 1317 (2005)

13. A. Kastengren, Christopher F. Powell, Z. Liu, S. Moon, J. Gao, X. Zhang, J. Wang, End-of-Injection Behavior of Diesel Sprays Measured With X-Ray Radiography. (ASME, 2010)

14. K. Wislocki, I . Pielecha, D. Maslennikov, J. Czajka, Kones, 18, 542 (2011)

15. A. Khalid, Effect of Ambient Temperature and Oxygen Concentration on Ignition and Combustion Process of Diesel Spray, Asian Journal of Scientific Research, 6, 434 (2013)

16. A. Khalid, K. Hayashi, Y. Kidoguchi, T. Yatsufusa, Effect of air entrainment and oxygen concentration on endothermic and heat recovery process of diesel ignition, (SAE International, 2011) 